\title{
Electro-Oxidation of Ciclopirox Olamine at a Glassy Carbon Electrode.
}

\author{
Mallikarjuna I.Hiremath ${ }^{\# 1}$ \\ Department of Post Graduation Studies in Chemistry, \\ Government Science College, (AutonomousHassan-573201, \\ (Affiliated to University of Mysore), Karnataka, India. \\ ${ }^{1}$ E-mail:mallikarjunahiremath4@gmail.com
}

\begin{abstract}
The electro-oxidation of Ciclopiroxolamine (CPO) has been studied at a bare glassy carbon electrode(GCE) in sodium hydroxide medium using the cyclic voltammetric technique(CV). The GCE shows an intensified electro chemical response towards the CPO by showing one oxidation peak in sodium hydroxide media. The effect of $\mathrm{pH}$, concentration, scan rates and surfactant were studied at the GCE. The limit of detection (LOD) and limit of quatitation (LOQ) of CPO were detected. The anodic peak potential $\left(E_{p}\right)$, anodic peak current $\left(i_{p}\right)$ was characterized. The electro-oxidation process was diffusion controlled.
\end{abstract}

Keyword - Ciclopirox olamine Cyclic voltammetry, , Glassy carbon electrode, Heterogeneous rate constant, Electro-oxidation.

\section{INTRODUCTION}

Ciclopirox olamine (CPO), 6-cyclohexyl-1-hydroxy-4-methylpyridine-2(1H)-one-2-hydroxyethyl)amino(1:1) (Fig.1) is used to treat fungal infections such as athletes foots and ring worms etc., It is most useful against Pityriasis[1]. It has a high potential disinfectant effect with less toxicity and strong osmolarity.<smiles>Cc1cc(C2CCCCC2)n(O)c(=O)c1</smiles>

Fig.1. Structure of $\mathrm{CPO}$

Various analytical procedures for the estimation of CPO using HPLC [5-6], microbial methods[8-9], pharmacokinetics[7-8], polarographic methods[9-10], and capillary chromatography[11] have been established. These methods are allows the generation of more microbes and presence of more colony forming units, contamination of the growth can occur, it doesn't allow the generation of obligate microorganisms. Investigations of the redox behavior of biologically occurring compounds through electrochemical techniques have the potential leading to detailed understanding of biological redox species of these compounds. Voltametric techniques are sensitive techniques and these are much used to know the electrochemical behaviour of such compounds [12-14].

In this paper a simple and sensitive procedure to study the electrochemical behaviour of CPO at GCE is presented and it under goes electro-oxidation at $\mathrm{pH}-4$ sodium acetate-acetic acid buffer.

\section{EXPERIMENTAL}

\section{A. Reagents and Chemicals}

Standard stock solution of CPO was prepared as follows $0.05 \mathrm{~g}$ of CPO is dissolved in $0.1 \mathrm{M}$ sodium hydroxide solution. During CV experiment, different known strength of CPO. were prepared by diluting the stock solution of CPO in the background electrolyte ( $\mathrm{pH}-4$ Sodium acetate- Acetic acid buffer).

\section{B. Apparatus and Procedure}

The electrochemical experiments were performed with CV Instrument,EA-201 Electro Analyser and were performed in a $20 \mathrm{ml}$ glass cell with a $3 \mathrm{~mm}$ diameter GCE as the working electrode ,a platinum wire as counter electrode and $\mathrm{Hg} / \mathrm{Hg}_{2} \mathrm{Cl}_{2}$ electrode as reference electrode. All experiments were performed at an encompassed temperature of $25 \pm 0.2^{\circ} \mathrm{C}$. The GCE is rubbed to make the electrode to free from from dust using $0.3 \mu$ aluminium oxide powder before each experiment. After rubbing, the electrode was washed completely with 
distilled water. After this mechanical treatment, the GCE was placed in $0.1 \mathrm{M} \mathrm{NaOH}$ electrolyte and various $\mathrm{CV}$ graphs were recorded until a consistent baseline graph was obtained.

The surface area dimension of the GCE was calculated using $10 \mathrm{mM} \mathrm{K}_{4}\left[\mathrm{Fe}(\mathrm{CN})_{6}\right]$ in $0.1 \mathrm{M} \mathrm{KNO}_{3}$ by recording the current voltage curve. From the cyclic voltametric peak current $(38.2 \mu \mathrm{A})$ and the diffusion coefficient of $\left[\mathrm{Fe}(\mathrm{CN})_{6}\right]^{4-}$, the area of the electrode was calculated [15-16] by using the equation.

$$
\mathrm{i}_{\mathrm{pa}}=\left(2.69 \times 10^{5}\right) \mathrm{n}^{3 / 2} \mathrm{~A} \mathrm{Do}^{1 / 2} v^{1 / 2} \mathrm{C}
$$

where, $n=$ number of electrons transferred, $A=$ surface area of the GCE, $D=$ diffusion coefficient $\left(6.538 \times 10^{-6} \mathrm{~cm}^{2} \mathrm{~s}\right.$ $\left.{ }^{1}\right), v=$ sweep rate $\left(0.02 \mathrm{Vs}^{-1}\right)$ and $\mathrm{Co}^{*}=$ concentration of electro active species $(10 \mathrm{mM})$. The surface area of the electrode was found to be $0.0392 \mathrm{~cm}^{2}$.

\section{III.RESULTS AND DISCUSSION}

\section{A. Electro-oxidation of $\mathrm{CPO}$}

The oxidative behaviour of $\mathrm{CPO}$ at a GCE was studied by cyclic voltammetry (CV) in $0.1 \mathrm{M} \mathrm{NaOH}$ as supporting electrolyte in pH-4 buffer of Sodium acetate -Acetic acid. In the studied potential range, the oxidative peak for buffer was not observed. The CV graph obtained for $0.44 \mathrm{mM} \mathrm{CPO}$ solution at a scan rate $\nu=100 \mathrm{mVs}^{-1}$ (Fig.2) shows one anodic peak that occur at $\mathrm{Ep}=0.75 \mathrm{~V}$. On scanning in the reverse direction, no reduction peak was observed, showing that the $\mathrm{CPO}$ undergoes oxidation only and hence it is an irreversible process. When the drug is subjected to several scans, it is observed that there is decrease in the oxidation current. This observation may be due to its adsorption of oxidative product of CPO on the surface of GCE (Fig.3). However, for CV experiment, the first scan was used.

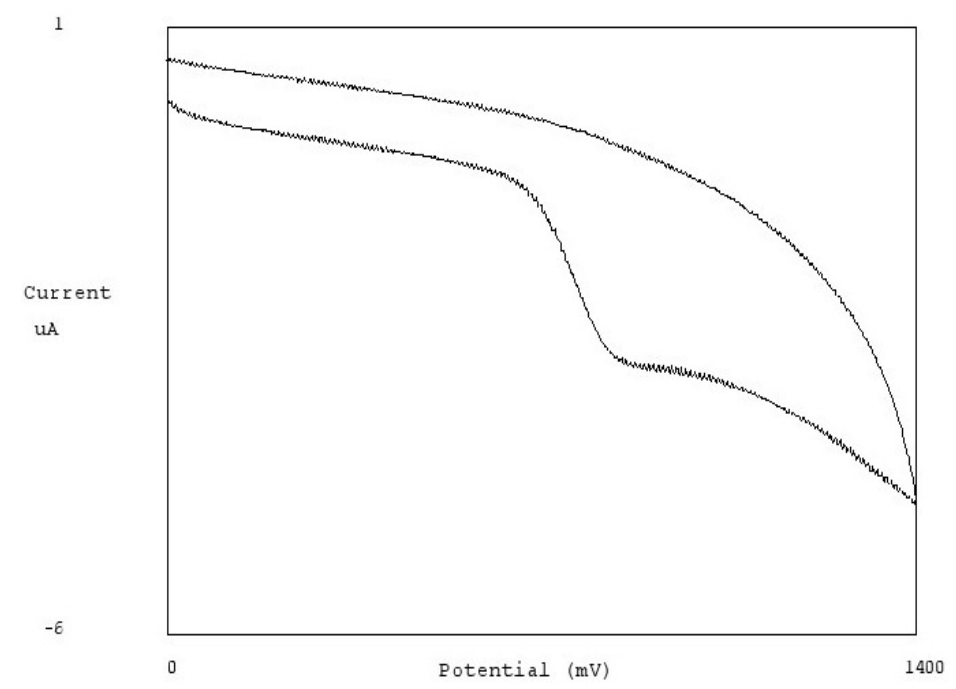

Fig. 2. Cyclic voltammogram obtained for $0.44 \mathrm{mM} \mathrm{CPO}$ on GCE in $0.1 \mathrm{M} \mathrm{NaOH}$ : (a)Ciclopirox olamine and (b) blank at $=100 \mathrm{mVs}-1$.

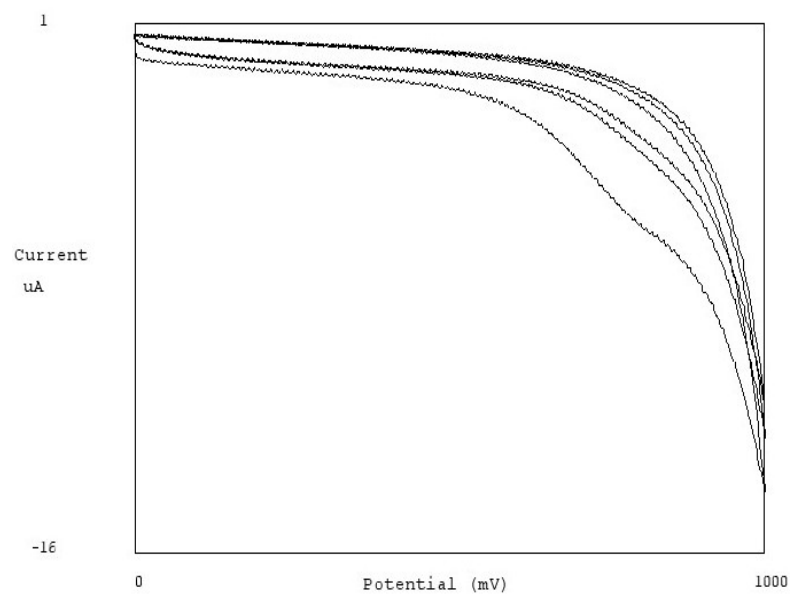

Fig.3. Successive cyclic voltammograms obtained for $0.44 \mathrm{Mm}$ CPO on GCE: (1) first, (2) second and (3) third scan at $v=50 \mathrm{mVs}^{-1}$. 


\section{B. Effect of scan rate}

The effect of rate of scan on the anodic oxidation of CPO was studied at a concentration of $0.44 \mathrm{mM}$ in $0.1 \mathrm{M}$ $\mathrm{NaOH}$ in $\mathrm{pH}-4$ Sodium acetate Acetic acid buffer. A log-log plot of peak current versus scan rate will give a slope $=0.5$ for diffusion and 1 for adsorption [17]. In all scanning the oxidation peak current was directly related to the square root of the scan rate. In such situation, the electro-oxidation phenomenon was Diffusion controlled. A linear relationship was observed between $\log$ ip and $\log v$ (Fig.4) corresponding to the equation: $\log \mathrm{i}_{\mathrm{pa}}(\mu \mathrm{A})=\operatorname{logv}+0.2517$, where $v$ is in $\mathrm{mVs}^{-1}$. The slope of 0.539 is close to the theoretically expected value of 0.5 for a purely diffusion -controlled current [16]. The graph of $i_{p a} / v^{1 / 2} v / s \log v$ shows that as the peak current increases along with sweep rate (Fig.5). This type of trend indicated that GCE surface has some adsorption issues.

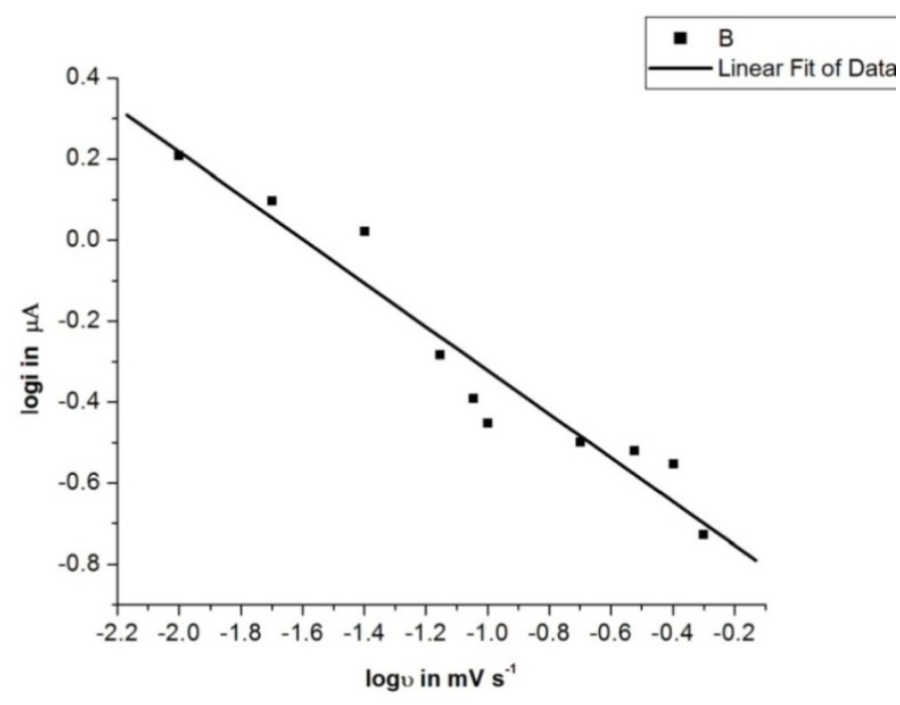

Fig. 4. Variation of the logarithm of peak current with the logarithm of the sweep rate for $0.44 \mathrm{mM} \mathrm{CPO}$.

The Ep of the oxidative signal was also dependent on scan rate. The graph of Ep v/s log $v$ was linear having a correlation coefficient of 0.9746 (Fig.6) and this behavior was consistent with the Electrochemical behaviour of the reaction. The relation between Ep and $v$ can be shown by the equation,

$$
\operatorname{Epa}(v)=0.27 \log v+0.81 \text {. }
$$

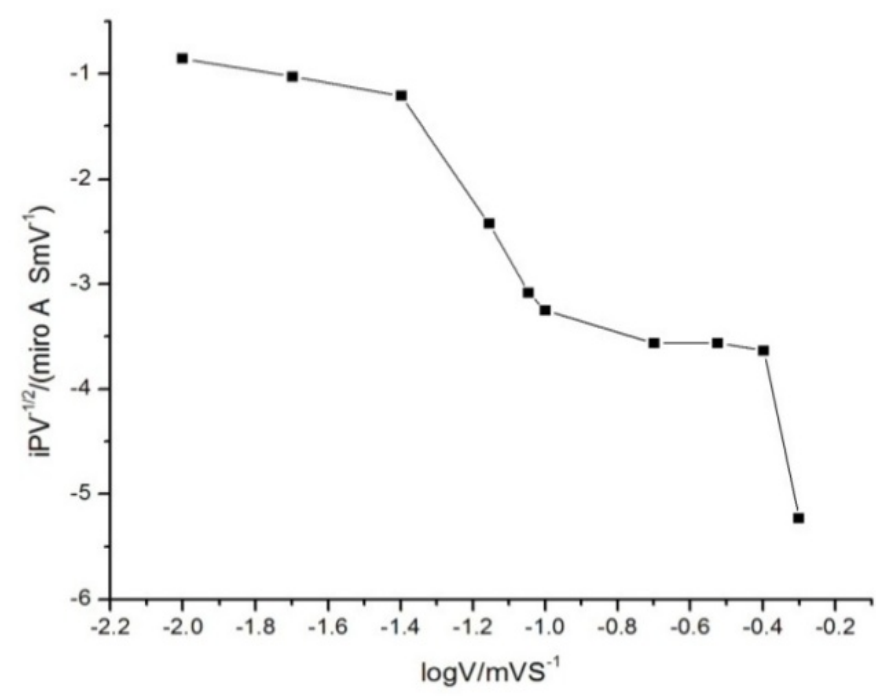

Fig. 5. Dependence of ip/ $/ v^{1 / 2}$ on $\log$ for $0.44 \mathrm{mM} \mathrm{CPO}$ at GCE. 


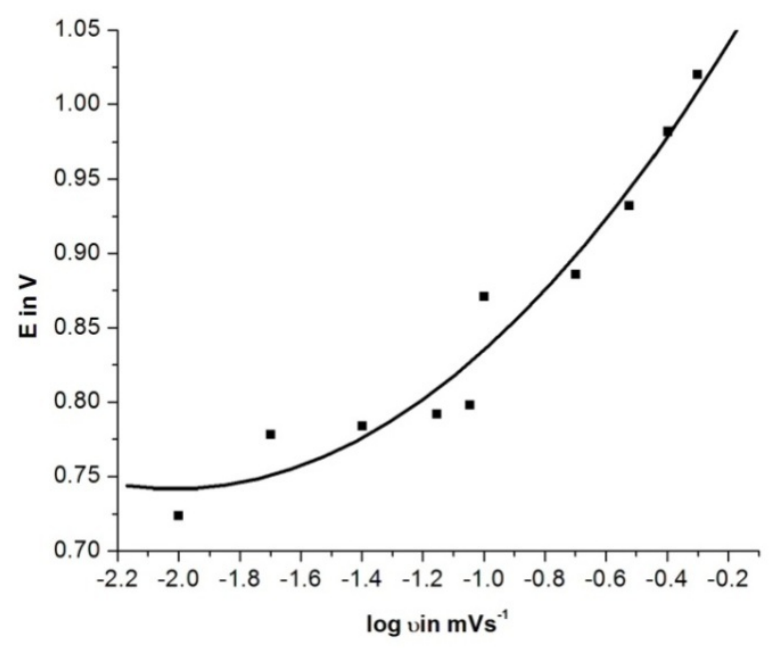

Fig. 6. Dependence of $E_{p}$ on $\log v$ for $0.44 \mathrm{mM}$ CPO.

\section{Effect of Concentration}

A plot of log Ipa vs different strength of CPO shows linearity (Fig.7), indicating further that the interaction of drug with GCE surface is observed through diffusion method [16], with correlation coefficient 0.929 . The linear relation expressing dependence of $\mathrm{i}_{\mathrm{pa}}$ on strength of $\mathrm{CPO}$ within limit between $0.44-1 \mathrm{mM}$.

The LOD and LOQ were obtained from the signal current using the relation $\mathrm{LOD}=3 \mathrm{~S} / \mathrm{M}$ and $\mathrm{LOQ}=10$ $\mathrm{S} / \mathrm{M}$ Where, $\mathrm{S}$ is the standard deviation and $\mathrm{M}$ is the slope (sensitivity) of calibration graph. The limit of detection (LOD) and limit of quantification (LOQ) of CPO were calculated as $4.303 \mu \mathrm{M}$ and $14.34 \mu \mathrm{M}$ respectively. Related statistical data of were taken from five calibration graphs $(\mathrm{n}=5)$.

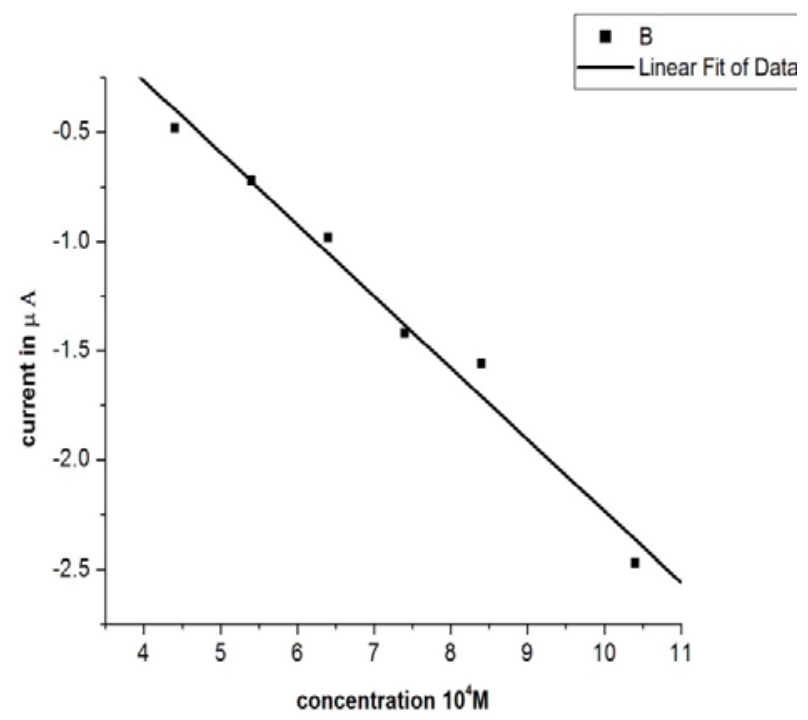

Fig. 7. Effect of strength of $\mathrm{CPO}$ on signal current at GCE. Sweep rate: $100 \mathrm{mVs}^{-1}$.

\section{Effect of Temperature}

The influence of temperature on electro-oxidation of CPO was performed at five temperatures (298-318K). Cyclic voltammograms of mixture of $\mathrm{CPO}(0.44 \mathrm{mM})$ and $0.1 \mathrm{M} \mathrm{NaOH}$ in $\mathrm{pH}-4$ Sodium acetate Acetic acid buffer $(0.1 \mathrm{M})$ were recorded at respective temperatures. The oxidation peak current increased linearly (Fig.8) with correlation coefficient 0.9658 . The heterogeneous rate constants $\left(k_{o}\right)$ were calculated at various temperatures by using the equation(3):

$$
i_{\mathrm{pa}}=k_{o}(0.227) \text { n F A C } \mathrm{o} \exp \{-\alpha \text { na }(\mathrm{Ep}-\mathrm{E})\}
$$

$i p=$ peak current $(\mu \mathrm{A}), \mathrm{n}=$ number of electrons involving in the process, $\mathrm{F}=$ Faraday constant $\mathrm{A}=$ Area of the

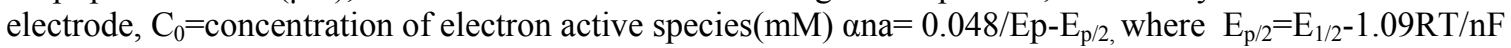




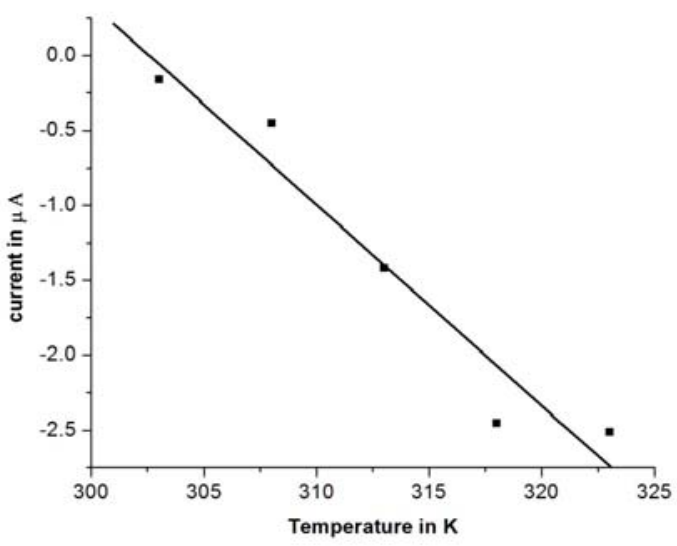

Fig. 8. Observed dependence of ipa on temperature for $0.44 \mathrm{mM} \mathrm{CPO}$

The Calculated heterogeneous $\mathrm{k}_{0}$ values are tabulated in Table.I. The energy of activation $\left(E_{a}\right)$ was evaluated from the Arrhenius graph of $\log \mathrm{k}_{\mathrm{o}}$ versus $1 / \mathrm{T}$, which was linear with the slope $=-4288.24$. (Fig.8). The other thermodynamic activation values were calculated from this Energy of activation value and are tabulated in Table.2.The less value of $\Delta \mathrm{H}^{\#}$ indicates the electro-oxidative process of CPO might be taking place through physical adsorption. The more $-\mathrm{ve} \Delta \mathrm{S}^{\#}$ value indicates the oxidation of CPO at electrode might be taking place via the formation of an activated adsorbed complex [18] before the products are formed. Such adsorbed intermediate complex is organized than reactant molecules itself.

TABLE I. calculated heterogeneous rate constants at 303 to $323 \mathrm{~K}$ for $0.44 \mathrm{M} \mathrm{CPO}$ with scan rate $100 \mathrm{mVs}^{-1}$ at GCE.

\begin{tabular}{|c|c|c|}
\hline Temperature in $\mathbf{K}$ & $\mathbf{i p} / \mathbf{\mu A}$ & $\mathbf{k}_{\mathbf{0}} \mathbf{x} \mathbf{1 0} \mathbf{5} \mathbf{c m ~ s}^{\mathbf{- 1}}$ \\
\hline 303 & 0.16 & 0.090 \\
\hline 308 & 0.45 & 0.097 \\
\hline 313 & 1.42 & 0.308 \\
\hline 318 & 2.45 & 0.525 \\
\hline 323 & 2.51 & 0.530 \\
\hline
\end{tabular}

TABLE III. Calculated thermodynamic activation parameters for the electro-oxidation of $0.44 \mathrm{mM} \mathrm{CPO}$ at GCE.

\begin{tabular}{|c|c|}
\hline Activation parameter & Values \\
\hline $\mathrm{Ea}\left(\mathrm{kJ} \mathrm{mol}^{-1}\right)$ & 8.319 \\
\hline$\Delta \mathrm{H}^{\#}\left(\mathrm{~kJ} \mathrm{~mol}^{-1}\right)$ & 5.7578 \\
\hline$\Delta \mathrm{S}^{\#}\left(\mathrm{JK}^{-1} \mathrm{~mol}^{-1)}\right.$ & -317.03 \\
\hline$\Delta \mathrm{G}^{\#}\left(\mathrm{~kJ} \mathrm{~mol}^{-1)}\right.$ & 97.69 \\
\hline
\end{tabular}

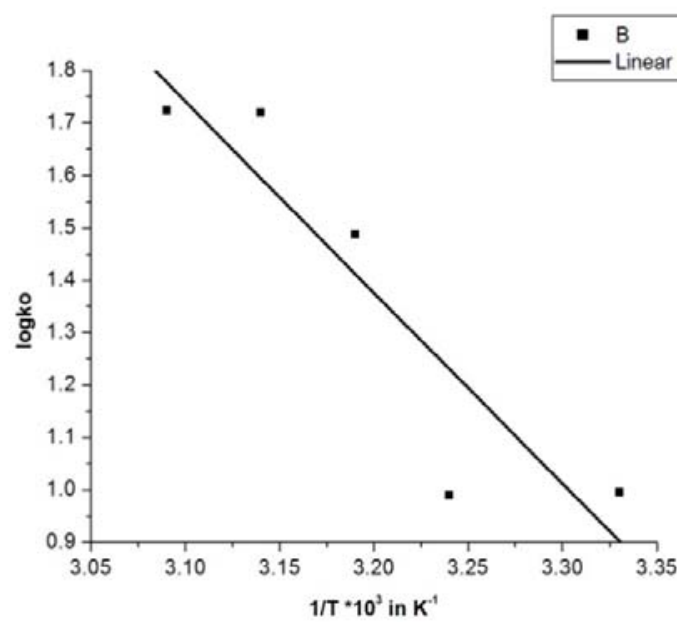

Fig.8. Effect of temperature on the electro-oxidation of $0.44 \mathrm{mM}$ Ciclopirox olamine with scan rate $100 \mathrm{mVs}^{-1}$ on GCE: Graph of log ko versus $1 / \mathrm{T}$. 


\section{E. Influence of $p H$}

$\mathrm{CV}$ was used to identify the dependence of $\mathrm{pH}$ value in the $\mathrm{CPO}$ at the GCE. The experiment on variation of $\mathrm{pH}$ was made between 3.7 to 5.6 in $0.1 \mathrm{M}$ Sodium acetate, acetic acid buffer solution at a scan rate of $100 \mathrm{mV} / \mathrm{s}$. at $\mathrm{pH} 4 \mathrm{Ep}$ was found to be high and then EPa values were decreasing with $\mathrm{pH}$ as given in Fig .(9). So $\mathrm{pH} 4.0$ was selected for further experiments.

\section{F. Influence of SDS Surfactant}

Surfactants in small quantities can exhibit a strong effect on the electrode process. Adsorption of such surfactants may hinder the electrode process, causes the obstacles while in CV graphs, and bring changes in the signal to more negative(-VE) potentials[19]. It clearly shows that the concentration of surfactants exhibits remarkable enhancement effect on the ipa of CPO. However, the ipa of CPO is closely related to the different amount of SDS $(1-5 \mathrm{ml})$. The oxidation and ipa enhances greatly as surfactants concentration was increased from $1 \mathrm{uL}$ to $5 \mathrm{~mL}$, the background current gradually increases while increasing the surfactants concentration. The graph of concentration vs. current shows linearity with correlation coefficient, SDS=0.942 Fig.(10).

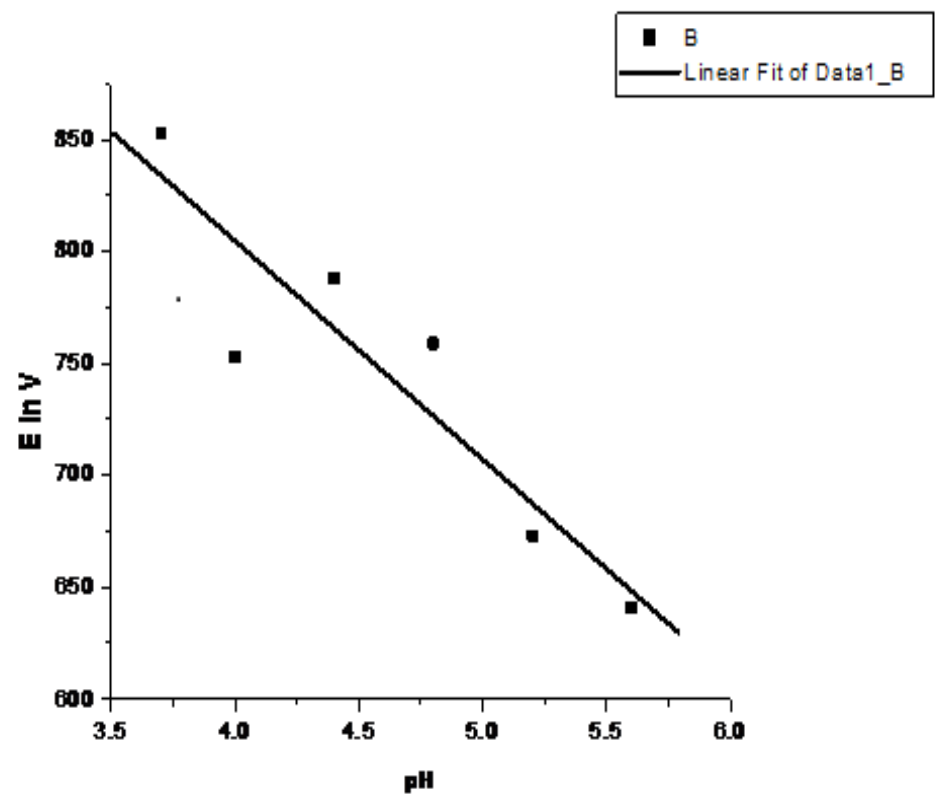

Fig. 9. Graph of the influence of $\mathrm{pH}(\mathrm{EP}$ vs. $\mathrm{pH})$

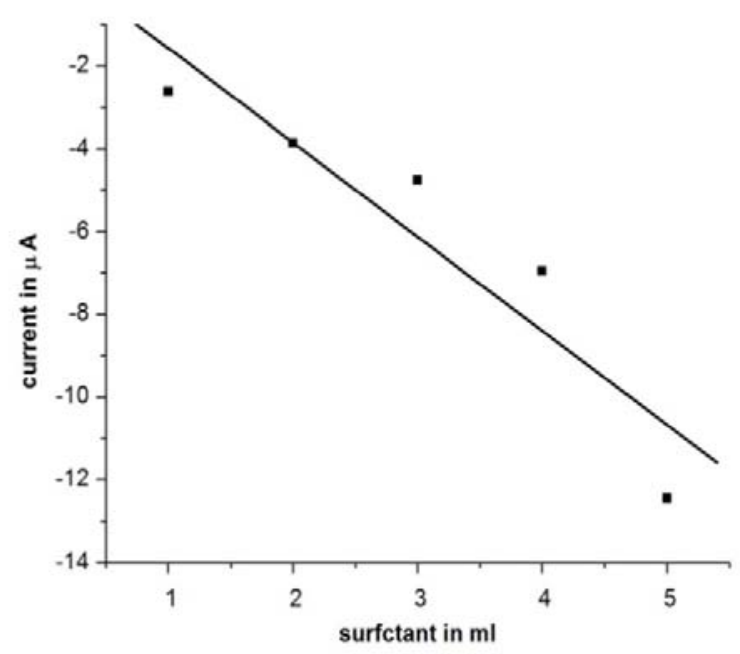

Fig. 10. Graph of the influence of SDS (current v/s surfactant in ml) 


\section{IV.CONCLUSION}

The presence of CPO at a GCE was established and studied for the first time. The process was irreversible at a high potential on a GCE. It is one of the best alternatives for the analytical determination of CPO because it is simple, fast, and inexpensive. Furthermore, This CV analysis method can be adopted for pharmacokinetic studies, also clinical and quality control laboratories.

\section{REFERENCES}

[1] S. H. Leem, J.E. Park, IS. Kim, J.Y.Chae, A.Sugino, Y. Sunwoo, "The possible mechanism of action of ciclopirox olamine in the yeast Saccharomyces cerevisiae,” Mol Cells.,vol. 28, pp. 55-61,2003.

[2] M.Niewerth, D. Kunze, M.Seibold, M.Schaller, H.C.Korting, B Hube, Ciclopirox olamine treatment affects the expression pattern of Candida albicans genes encoding virulence factors, iron metabolism proteins and drug resistance factors," Antimicrobial Agents Chemother," vol. 47,pp. 1805-17,Jun. 2003.

[3] R.C. Ratnavel, R.A. Squire, G.C. Boorman, "Clinical efficacies of shampoos containing ciclopirox olamine (1.5\%) and ketoconazole $(2.0 \%)$ in the treatment of seborrhoeic dermatitis," J Dermatolog Treat., vol.18(2),pp.88-96,2007.

[4] F.Crawford, S.Hollis, "Topical treatments for fungal infections of the skin and nails of the foot," Cochrane Database Syst Rev., vol.18, CD001434, Jul.2007.

[5] L. Gagliardi, G. Multari, G. Cavazzutti, D. De Orsi \& D.Tonelli, HPLC determination of ciclopirox, octopirox, and pyrithiones in pharmaceuticals and antidandruff preparations,”Journal of Liquid Chromatogrophy \& Related Technologies.,vol. 21, 1998.

[6] P.Chouhan, T.R.Sini, "Development and validation of a HPLC method for diretct estimation of ciclopirox olamine in Ex Vivo transungual permeation studies," Indian Drugs.,vol.53,pp.32-39,2016

[7] Khalida Rizi, Sudaxshima Murdan, A.Cynthia, Danquah Jame faull Sanjib Bhakta," Development of a rapid,reliable and quantitative method-“SPOTi” for testing antifungal efficacy,”Journal of Microbial Methods.,vol.117,pp.36-40,2015.

[8] D.C.Katrina Kokjohn,M.S.Mary,Bradley,B.S.Brain Griffiths,Mahmoud Ghannoum, "Evaluation of in vitro activity of ciclopirox olamine,butenafine HCL and econazole nitrate against dermatophytes, yeasts and bacteria," Journal of Dermatology., vol.42,pp.1147,2003 .

[9] F. Ibrahim, N. El-Enany,"Polarographic determination of ciclopirox olamine in pure substance and in different pharmaceutical preparations" II Farmaco.,vol.58, pp.1313-1338,2003.

[10] F. Ibrahim, N. El-Enany,"Anodic polarographic determination of ciclopirox olamine in pure and certain pharmaceutical preparations," Journal of Pharmaceutical and Biomedical Analysis, vol.32, pp.353-359, 2003.

[11] Junmei Li, Ye Jiang, Ting Sun, Shumeng Ren, "Fast and simple method for assay of ciclopirox olamine by micellar electrokinetic capillary chromatography,” Journal of Pharmaceutical and Biomedical Analysis., Vol.47, pp. 929-933, August 2008.

[12] Run-Xia He, Da-Wei Zha., "Cyclic voltammetry and volt absorptometry studies of redox mechanism of lumazine Journal of Electroanalytical Chemistry," vol.791, pp.103-108, 2017.

[13] Zouhour Denden, Wafa Harhouri, Leila Ben Haj Hassen, Yoann Rousselin, Eric Saint-Aman, Habib Nasri, Synthesis, spectroscopic, cyclic voltammetry properties and molecular structure of the thiocyanato-N meso-tetratolylporphyrinato zinc(II) ion complex,"Journal of Molecular Structure.,vol. 1133,pp.472-478, 2017.

[14] M.Carla,Oliveira,S.Antonio,Barros,C.S.Antonio Ferreira,M.S.Artur Silva, "Study of quinines reactions with wine nucleaophies by cyclic voltammetry," Food Chemistry.,vol.211,pp.1-7,2016.

[15] Keerti M.Naik,Sharanappa T,Nandibewoor, "Electrochemical behaviors of chalcone at a glassy carbon electrode and its analytical applications,” American Journal of Pharmaceutical Sciences.,vol.3,pp.656-663,2012.

[16] Jayant I.Gowda,Sharanappa T.Nandibewoor, "Electrochemcal behavior of pacletaxel and its determination at glassy carbon electrode," Americal Journal of Analytical Chemistry., vol.3,pp.656-663,2012.

[17] D.K.Gosser(Ed),Cyclic Voltammetry,VCH,New York,1994.

[18] W.J.Moore,Physical Chemistry, $5^{\text {th }}$ ed.Orient Longman Pvt Ltd,New Dehli,2004.

[19] J.Herovsky, and J. Kuta, Principles of Polarography., Academic Press, New York, 1966

\section{AUTHOR PROFILE}

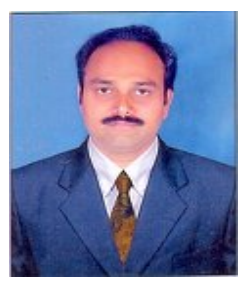

Dr.Mallikarjuna Ishwarayya Hiremath, presently serving as Assistant Professor at Department of Post Graduation Studies in Chemistry, Government Science College (Autonomous), Hassan-573201, (Affiliated to University of Mysore) Karnataka, India. He obtained Master degree in Chemistry in 2002 from Karnataka University Dharawad (KUD), Karnataka. He was awarded Ph.D. degree in Chemistry from KUD in 2006. He is actively engaged in research in the field of Physical Chemistry in general and Chemical Kinetics \& Electrochemistry in particular. Recently, he has been honoured "Emerald Who's who in Asia". 